The Geneva Papers on Risk and Insurance, 14 (No. 51, April 1989), 207-212

- DOCUMENT -

\title{
Financing the Clean-up of Hazardous Waste: The National Environmental Trust Fund
}

\author{
by Maurice R. Greenberg*
}

One of the most crucial public policy problems facing America today is the gridlock that has tied up our national attempt to deal with environmental pollution. While virtually every sector of our society recognizes the need to clean up the environment, little has been done to fulfill that mandate.

At the root of this inaction is an overriding issue: How do we pay the immense cost of correcting the damage done by past waste handling practices? There is, therefore, a profound need to reexamine the fundamental aspects of this question - and to seek new answers to replace the old ones that have proven ineffective.

The timing is right for this effort. Congress must reconsider our key environmental clean-up legislation - Superfund - in 1991, and the discussion leading up to that has already begun. In addition, this year Congress will also consider the Resource Conservation and Recovery Act, which governs the disposal and treatment of waste materials.

A good way to start the process of reevaluating our approach to cleaning up the environment is to recognize the past effect of pollution for what it largely is : The residue of progress. Most of today's ground and water contamination did not result from deliberate, conscious acts but is an unintended result of our economic history.

America's industrial expansion in the post-war era, as well as in prior periods, has given us a standard of living unprecedented in world history. Our industrial development has created the jobs that underpin the well-being of individuals and their families - and has financed the public and private institutions that we value as a part of our national social fabric.

But as our industries grew, the by-products they discharged coalesced into waste sites that now dot our national landscape. This presents us with one of the truly urgent imperatives of our time: To eliminate these accumulations so we restore the environment and move forward to seize the economic opportunities of the future.

It is difficult to overstate the scope of this challenge. U.S. Government studies show that as many as 425,000 potentially hazardous waste sites may need to be investigated. Not all of these, of course, will require action.

* President and Chief Executive Officer, American International Group, Inc., Wew York. Text presented in Washington, D. C., on March 2, 1989. 
While it is not possible at this point to determine the exact cost of cleaning up the sites requiring correction, it is obvious that the expense will be enormous. The estimates generally vary from $\$ 150$ to $\$ 700$ billion, depending upon the number of sites and other factors used in the estimates.

However, we do know that at least $\$ 25$ billion will be required just to correct the approximately 1,000 waste sites that have been identified as requiring urgent action.

Against this backdrop, one thing is clear: Our response to the pollution crisis has been weak and ineffective. The Superfund legislation was enacted in 1980 and renewed in 1986. The intent in the renewal was to start work on 375 of the some 1,000 most hazardous waste sites. Yet, to date, clean-up at only 27 has been completed - and many observers question the effectiveness of what has been done at those few locations.

In a report issued in June 1988, the U.S. Office of Technology Assessment called the Superfund program "largely ineffective, inefficient." In a more recent report, the General Accounting Office said, "It is doubtful that the Superfund program, as currently operated, will ever achieve the clean-up of all hazardous waste sites."

Environmental groups such as the Sierra Club and the Audubon Society have similar concerns. This is understandable since there is no debate over whether or not the environment must be corrected - but over how.

This argument about methodology is reflected in the broad course of events since the creation of Superfund eight years ago. Instead of restoring the environment, the Superfund effort has deteriorated into a morass of legal warfare involving industry, government at all levels, environmental groups and insurance companies.

As a result, large amounts of energy and money have gone into complex and protracted litigation - and the job of fixing the environment has largely stalled out. Remarkably, studies indicate that of the total funds spent since 1980 on environmental matters, something between 30 and 60 percent has gone for legal expenses. It's impossible to determine the exact figure, but that's an astounding amount of money at even the lower end of the range.

Authorities frequently comment that environmental litigation is the premier area of growth within the legal profession. This field has given rise to its own trade press, there are seminars almost daily on the subject and environmental-related courses in the nation's law schools have grown considerably.

It's little wonder that we've made such poor progress in achieving our national public policy objectives relating to pollution. Most of the action is taking place in the courtroom instead of at the hazardous waste sites.

\section{An Inevitable Consequence}

With the clarity of hindsight, we can see that this tragic result is the inevitable consequence of the basic Superfund concept. Under that approach, the Environmental Protection Agency has the authority to identify and correct hazardous waste sites. As part of this charter, it can sue the party or parties it deems responsible for the pollution. This may sound reasonable, but it has proven to be seriously flawed for four basic reasons. 
First, Superfund's ability to assess and collect funds for environmental cleanup is founded on the principle of strict retroactive liability. This means that companies are now being held responsible for environmental damage that occured 20 or 30 years ago - or even longer.

It is important to stress that this liability is being imposed even when those responsible did not violate any laws when disposing of their wastes. The environmental regulations that we take for granted today simply did not exist then.

We should also recognize that, in the majority of cases, these companies were not acting in a deliberate or irresponsible way. At the time, they were not aware of the future consequences of their waste disposal practices. And, business was not alone in this ignorance. Otherwise, federal, state and local governments would have enacted laws to govern the handling and disposal of waste.

It is, therefore, understandable that companies should now bridle at being held responsible for actions that occurred long in the past - and which were not illegal, deliberate or irresponsible at the time.

Moreover, it is not an entirely valid argument to assert that those who profited from the careless waste disposal should now be made to clean it up. We all "profited" by it at the time in the form of rapid economic growth, more jobs and lower prices for the consumer. In addition, where the pollution occurred a decade or more in the past, we may be talking about a largely new set of shareholders, new directors and new management - perhaps few or none of whom directly participated in the profits of the polluting corporations.

The second factor obstructing the Superfund effort is the extreme difficulty of finding out who is responsible for pollution. In most cases, the damage occurred over several decades.

Compounding the difficulty is the fact that many of the hazardous waste sites on the EPA's priority list are common dumping areas used by dozens or even hundreds of companies, individuals and municipalities.

Consequently, states, municipalities and the federal government are spending huge sums in an attempt to find polluters and fix liability. Since this frequently can't be done with any certainty, the prevailing philosophy is to pursue any party that has any connection to a waste site, however tenuous. That may be a manufacturer who is using or has used the property, a waste transporter, a current or past landowner, a bank that financed the property, a real estate developer or a land manager.

This environmental wild goose chase is the principal reason that the transactional costs of Superfund - that is the money being spent to identify polluters - have spun out of control.

The third factor reducing the effectiveness of our current approach to pollution is the sheer magnitude of the costs involved. With the price of cleaning up a hazardous waste site ranging from several million to several billion dollars, a simple fact emerges: No one party, either in the private ou public sector, can be expected to bear the entire brunt of the environmental clean-up job.

If individual companies are held responsible, the result in some cases could be bankruptcies. That would, of course, be an extreme consequence. But even major corporations stagger under the strain of mammoth pollution costs. When that happens, the penalty for 
the economy is fewer new jobs created and a reduced ability to compete internationally. That is an unfortunate consequence. If we permit it to continue unchecked, we may permit pollution to have still another serious effect: A weakening of our national economic power.

To be sure, we cannot turn to government to pay for cleaning up the environment. The outsized federal budget deficit that now commands national attention - as well as the intense financial pressure on state governments and municipalities - put that out of the question.

\section{A Legal Storm}

The fourth factor inhibiting our environmental program is one alluded to at the outset of this discussion: The legal storm that has whipped up around the pollution problem. Government is suing business. So are those adversely affected by pollution, as well as environmental groups. Business, in turn, is suing its insurers.

This situation has resulted from the difficulties inherent in the concept of retroactive liability, the problem of identifying responsible parties and the enormous costs involved. Everyone, it seems, has gone to court.

In one case, a corporation is suing 240 of its insurers who provided coverages over the past 37 years. In another, a company has lodged claims against more than 140 of its insurers. A third has a corporation suing 270 insurers.

If all this sounds like a debacle - it is. The battle involves such arcane, but legally significant issues as whether the pollution is gradual or sudden in nature - and how you define "gradual" and "sudden".

The genuine problem, however, is that in writing general liability policies in the past, insurers did not assess any risks related to gradual pollution, nor did they include in the overall premium any charge for such risks. The reason is simple: In earlier periods, there were few, if any, laws to define pollution or to make it a violation. Therefore, no coverage was needed.

Sensing the public policy void created by the maelstrom of this litigation, the courts often have stepped in and have taken it upon themselves to make environmental law where none exists. The tendency in many cases has been to view the insurance industry as a sort of public treasury when there is no other source of funds to pay for rectifying environmental damage.

But that is no solution either. This becomes evident when you recognize that the estimated costs necessary to correct our environmental damage exceed the total surplus of the entire U.S. insurance industry.

This brings us to the central question: If individual businesses, government or the insurance industry are not in a position to pay for cleaning up the pollution mess, who is? An answer to that is essential if we are to take a new and more productive route to dealing with pollution.

One thing is certain: Solutions will remain elusive if we continue to address the environmental clean-up issue as we have in the past. It makes no sense to force individual parties to shoulder a substantial financial burden when they have not violated any laws or regulations or acted in an irresponsible, deliberate way. 
In short, the attempts to fix blame and liability must be replaced by a sense of shared purpose among those involved in the pollution question: Government, private industry, insurers and environmental groups.

In view of what has gone on before, this may seem difficult to do. But, we believe it is possible to achieve a consensus if we recognize the premise stated at the outset of this discussion: That is, the pollution damage of today is the residue of progress made in a past era. Viewed in this perspective, it is reasonable to conclude that since society as a whole benefited from our prior progress, society as a whole should assume the burden of cleaning up the by-product of that progress.

If we can agree on that, we can replace the current inaction on pollution with a system that is effective, economically sound and politically acceptable. The key is to devise an approach that spreads the costs more broadly and reduces as much as possible the current legal warfare over the environment

\section{The National Environmental Trust Fund}

The basic elements necessary to do this are already in place. The system we propose is based on the concept of a National Environmental Trust Fund. This would be a dedicated, protected fund like the Highway Trust Fund. It would be used only for its stated purpose that is, to finance the clean-up of the highest priority hazardous waste sites created by past pollution.

At this point, it should be emphasized that the National Environmental Trust Fund would be established only to deal with the existing sites created by waste disposal occurring in the past. The Trust Fund would not apply to any environmental damage occurring henceforth. This solution also would not apply to environmental damage caused by deliberate, conscious acts of pollution where it is clear who is responsible.

In other words, the National Environmental Trust Fund would deal only with old waste sites where there is no evidence that regulations existing at the time of the pollution were violated. All cases involving deliberate actions and the cases occurring henceforth would be dealt with on the legal basis of strict liability.

Even with those exceptions, the Trust Fund would eliminate a significant portion of the pollution lawsuits. A large volume of the cases in process now, and those that will occur in the future, relate to old waste sites where it is not clear who is responsible for the damage.

Here's how the National Environmental Trust Fund could work: A separate, earmarked fee could be added to all the commercial/industrial property-casualty insurance premiums paid in the United States. In addition, some method of payment could be established for those corporations that are self-insured. They could be assessed on a premiumequivalent basis derived from any number of factors.

Of course, insurance companies would bear their share of the cost. They, too, pay premiums - both in-house and to other companies as well - and the fee would apply in those cases. In addition, insurers would be assessed for their self-insurance on the same basis as any other corporation.

Based on our research, even a modest premium-based fee - say on the order of two percent and the equivalent for self-insureds - could raise an average of $\$ 3$ billion annually 
over ten years. That would be enough to capitalize the National Environmental Trust Fund at $\$ 40$ billion over the next decade.

This amount is sufficient to clean-up the first 1,000 known priority hazardous waste sites, with enough left over for the additional sites that are expected to be identified over the next ten years.

These funds would be collected by insurance companies and remitted to the Environmental Protection Agency, which would be responsible for administering the program. The National Environmental Trust Fund thus would not require a new government agency or an expensive and complex collection system.

\section{New Tax Not Required}

Significantly, this plan does not require a new tax. Instead, it would substitute a flat fee for the current complex - and inequitable - method of taxation used to finance Superfund. We thus are not proposing that Superfund be discarded, but rather that it be given a new and more effective way to finance its mission.

The flat fee approach avoids the need for court decisions or regulatory agencies to assign degrees of responsibility according to how much a class of business or industry has contributed to past pollution. As previously noted, environmental damage that occurred in the past is a problem we all share. We thus need to put a stop to the endless debate, and the expenditure of huge sums of money, aimed at determining who is responsible for the old waste sites. Instead, we need to spend the money and effort on cleaning up the contamination.

In summary, this is the broad outline of a new direction we can take to solve an old problem that, until now, has proven intractable. We have purposefully presented the proposal in a general form in the hope that it will stimulate a national discussion on a new way to restore the environment. We now encourage reaction and suggestions from all parties concerned with hazardous waste, with the hope that a broad consensus will evolve around a more detailed approach. This dialog should focus on three fundamental aspects of the National Environmental Trust Fund:

One, it would eliminate a large portion of the legal costs associated with environmental clean-up. This would result since there would be less incentive to assess liability related to the old, known and often abandoned hazardous waste sites.

Two, the transactional costs associated with Superfund - namely, the money spent to find polluters - would be vastly reduced. We would also be able to get on with the clean-up job without wasting more time.

Three, the cost of restoring the environment would be spread more evenly across society so that no one sector - or the economy in general - suffers an unbearable financial burden.

When you bring these factors together, you get this vital result: More money would be available for the assault on pollution, and we could remove the obstacles that have produced our current environmental gridlock. We should therefore move forward to develop and implement the National Environmental Trust Fund as quickly as possible. 